RESEARCH ARTICLE

\title{
Haematological and biochemical changes associated with male rats deprived of feed and water
}

B.S. Okediran*, S.A. Amid, F. Sanusi and K.O. Oladesu

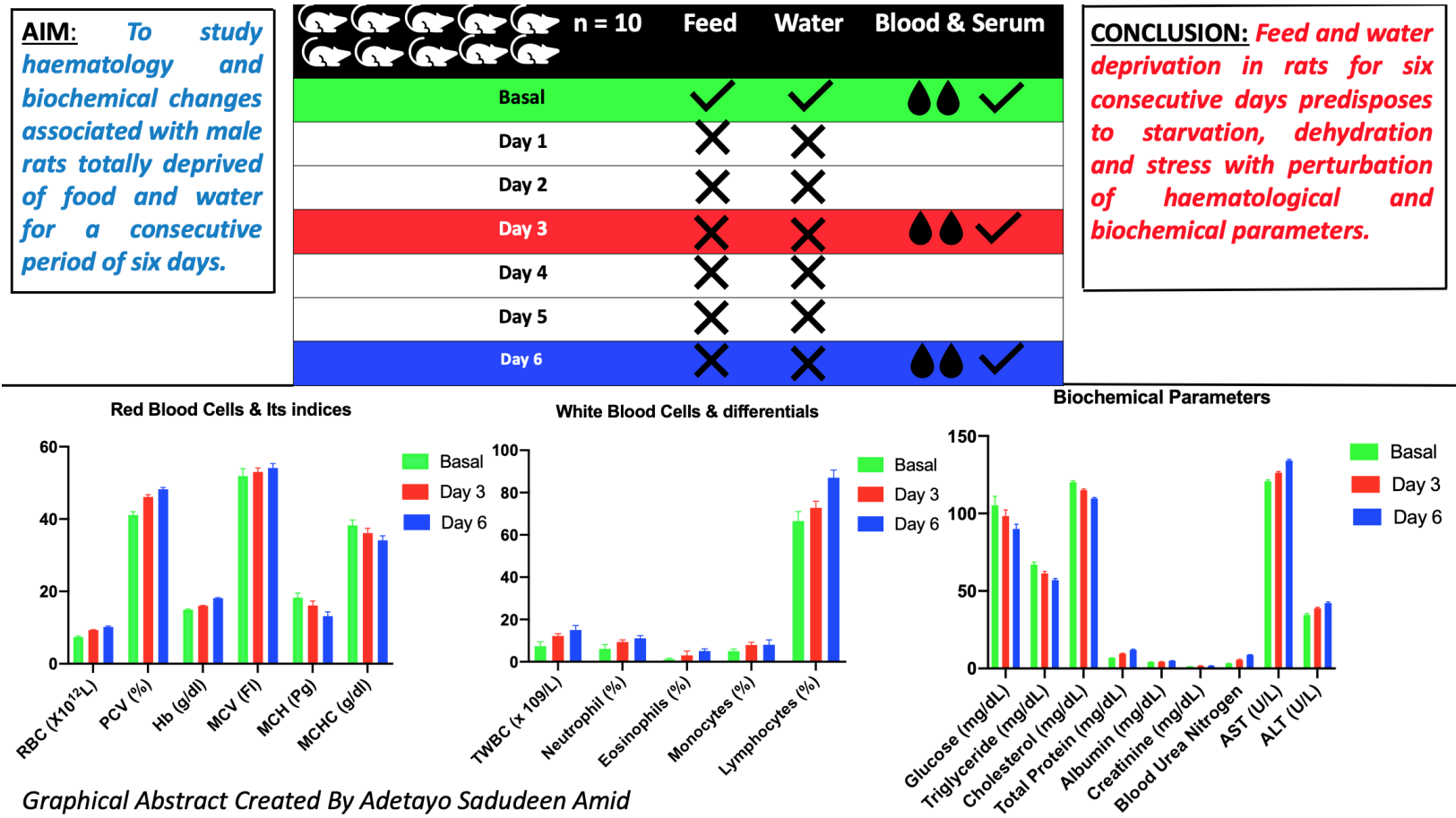

\section{Highlights}

- Feed and water deprivation in rats for 6 days led to haemato-biochemical alterations.

- $\mathrm{RBC}, \mathrm{PCV}, \mathrm{WBC}, \mathrm{HbC}$ and MCV increased significantly when compared to the control.

- Neutrophils, eosinophils, monocytes and lymphocytes counts rose more than normal.

- $\mathrm{MCH}, \mathrm{MCHC}$, glucose, triglyceride and cholesterol dropped below basal parameters.

- TP, albumin, creatinine, BUN, AST and ALT levels were increased above normal values. 
RESEARCH ARTICLE

\title{
Haematological and biochemical changes associated with male rats deprived of feed and water
}

\author{
B.S. Okediran", ${ }^{1, *}$ S.A. Amid ${ }^{2}$, F. Sanusi ${ }^{1}$ and K.O. Oladesu ${ }^{1}$
}

${ }^{1}$ Department of Veterinary Physiology and Biochemistry, Faculty of Veterinary Medicine, University of Ilorin, Ilorin, Nigeria.

${ }^{2}$ Department of Veterinary Surgery and Radiology, Faculty of Veterinary Medicine, University of Ilorin, Ilorin, Nigeria.

Received: 20/06/2020; Accepted: 10/01/2021

\begin{abstract}
Overnight food and water restriction protocols are common in animal research, however information about the haematological and biochemical changes due to food and water deprivation over longer periods can provide information about the stress experience by these animals. This study was conducted using ten $(\mathrm{n}=10)$ male albino rats housed in metallic cage. The rats were deprived of feed and water consecutively for six days. On the third and sixth days blood samples were obtained for haematological studies while serum was used for biochemical studies. There were significant increases in red cell counts, packed cell volume, haemoglobin concentration and mean corpuscular volume while significant decreases were observed in the mean corpuscular haemoglobin and mean corpuscular haemoglobin concentration as compared to the basal parameters. The white blood cells, neutrophils, eosinophils, monocytes and lymphocytes were significantly increased as compared with the basal parameters. Activities of aspartate and alanine aminotransferase in post feed and water deprivation condition are elevated compared to basal parameters. There were significant decreases in serum glucose, triglyceride, cholesterol concentrations while the total protein, albumin, creatinine, blood urea were significantly elevated. It can be concluded that rats deprived of feed and water predisposes to starvation, dehydration and stress with perturbation of haematological and biochemical parameters.
\end{abstract}

Keywords: biochemical; deprivation; feed; haematology; water.

\section{INTRODUCTION}

Feed and water deprivation is a common procedure performed in association with many different types of experiments mainly in order to reduce variability in investigatory parameters or to facilitate surgical procedures. An animal satisfies its needs for food and water, not just because it experiences an acute feeling of thirst or hunger, but also because it has learned to realize its needs and knows how to meet them within the provisions of the environment in which it lives (Tucci et al., 2006). If the absence of food or water is not dramatic or long lasting, the temporary effects this has on the animal's metabolism or hydration status will have little effect on the animal's welfare. The critical factor is whether the animal learns to change its behaviour to adapt to the availability of food and water over time (Toth and Gardiner, 2000). This situation is common in the wild and also exists in laboratory experiments when food is rationed. These adjustments are often well tolerated as long as they are within limits to which the animal can adjust. A totally different situation arises if the animal is subjected to sudden, unexpected and chronic food deprivation (Bauer et al., 2004).

Feed and water deprivation leads to some changes in one's eating habits, the amount of received energy and physiological parameters in the blood, however the body continually makes innumerable large and small adjustments to internal and external changes in its environment, to offset changes that threaten to create an abnormal state (Kanizsai et al., 2004). Many of these adjustments are easily visible and relatively dramatic, but still well within what may be defined as 'normal'. The regulation of cellular nutrition during and between meals is an example of these adaptations. As long as the animal is given sufficient food as often as it is accustomed to, these changes are physiological (Stricker, 1984). If however, the supply of food deteriorates significantly (in quality or quantity), the body will no longer be able to regulate its functions within normal limits and pathological conditions will arise. An animal will notice changes in its supply of food rapidly, and this may lead to psychological stress. The degree of stress, in relation to feed and water deprivation, will depend upon the species and also for animals in captivity (Hughes et al., 1994).

Fasting can be expected to cause, among other things, stress, aggressive behaviour, as well as reductions in body weight, body temperature and plasma glucose levels. A reduction in basal metabolic rate, which persists after the period of fasting, has been reported (Penicaud and Le Magnen, 1980). The effect of food deprivation is greatest when it occurs in the dark phase, when the animals are most active, significant reductions in liver weight and glycogen content, as well as increases in levels of glycerol, free fatty acids and acetoacetate have been measured after three hours (Palou et al., 1981). Claassen (1994) reported increases in plasma levels of glucose, urea, lactate and amino acids, a range of hormones including insulin, glucagon and corticosterone, as well as increased activity in the sympathetic nervous system. 
Food and water deprivation has been shown to cause some changes in hematological and biochemical parameters in blood, however its effect on biochemical parameters is still a matter of debate, it was reported that energy intake decreases during fasting (Sweileh et al., 1992). The commonest haematological and biochemical data available were rats or animals subjected to overnight or maximum of five to six hour feed and water deprivation in which varying physiological changes were observed. This study is to provide a more complete picture of haematological and biochemical changes associated with male rats totally deprived of food and water for a consecutive period of six days.

\section{MATERIALS AND METHODS}

\section{Animal ethics}

All experimental protocols carried out on the animals were in accordance with the international accepted principles for laboratory animal use and were approved by the Ethics Committee (UIL/FVERC/001/2020) on Laboratory animal use of the Faculty of Veterinary Medicine, University of Ilorin, Nigeria.

\section{Experimental animals}

A total of ten $(n=10)$ male albino rats were used for this investigation. The average weight of the rats was $152 \pm 3.50$ g. These rats were housed in metallic cage under standard room temperature $\left(20.0{ }^{\circ} \mathrm{C}\right)$ and pressure $(760 \mathrm{mmHg})$. They were provided with laboratory animal feed (Fat/oil $6 \%$, crude fibre $5 \%$, calcium $1 \%$, Available phosphorus $0.4 \%$, Lysine $0.85 \%$, Methionine $0.35 \%$, Salt $0.3 \%$, Crude protein 18\%, Metabolizeable Energy $2900 \mathrm{Kcal} / \mathrm{kg}$ manufactured by TOPFEEDS $®$ (Lagos, Nigeria) and water provided. Experimental animals were acclimatized to their environment before the start of the experiment.

\section{Haematological and biochemical parameters}

Basal haematological and biochemical parameters were determined before the animals were deprived of feed and water. The animals were deprived of feed and water for six consecutive days. Blood samples were collected on the third and sixth day for haematological and biochemical analyses.

\section{Haematology}

Aliquot of blood sample was collected into EDTA bottle for determination of packed cell volume, red blood cell and white blood cell counts as described by Schalm et al., (1975).

\section{Serum preparation}

Aliquots of blood samples were collected into plane tubes and centrifuged at $4000 \mathrm{rpm}$ for 10 minutes to separate the sera from the cellular components. The sera were then decanted and stored in Eppendorf tubes for further analyses as described by Schalm et al., (1975).

\section{Biochemical analysis}

Blood glucose concentrations were checked by caudal vein blood sampling and using Bionime glucometer. Total serum protein and albumin concentrations were estimated using Randox ${ }^{\circledR}$ commercial biochemical kits (Randox ${ }^{\circledR}$, Spain) as described by Tietz (1995) and Grant (1987) respectively. Blood urea nitrogen and creatinine concentrations were estimated using Randox ${ }^{\circledR}$ commercial biochemical kits as described by Henry (1974). The aspartate and alanine aminotransferases activities were assayed as described by Reitman and Frankel (1957), while serum triglyceride and cholesterol concentrations were determined as described by McGowan et al., (1983) and Wybenga et al., (1970) respectively.

\section{Statistical analysis}

Results were expressed as mean \pm standard error of mean. Analysis of the data was done using one-way analysis of variance followed by the Duncan multiple range test. A $\mathrm{p}<0.05$ was considered significant. All analyses were done using Graph Pad Prism Version 5.

\section{RESULTS}

Table 1 shows the red blood cells and it indices in male rats deprived of feed and water for six consecutive days. There were significant increases $(p<0.05)$ in red cell counts, packed cell volume and haemoglobin concentration compared to the basal parameters. However there was significant increase in mean corpuscular volume, but significant decreases were observed in the mean corpuscular haemoglobin and mean corpuscular haemoglobin concentration compared to the basal parameters.

Table 2 shows the total and differential leucocyte counts white cells counts of rats deprived of feed and water for six consecutive days. Total and differential leucocyte counts are increased.

Table 3 shows the biochemical parameters of male rats deprived of feed and water for six consecutive days. There was a marked decrease in serum glucose concentration especially on the sixth day post feed and water deprivation compared to the basal parameter. However, the lipid parameters, triglyceride and cholesterol were significantly $(p<0.05)$ decreased compared to the basal parameters.

The total protein and albumin are mildly but significantly increased compared to the basal parameters, while creatinine and blood urea showed a mild increase post feed and water deprivation compared to the basal parameters.

There was a significant $(\mathrm{p}<0.05)$ increase in the activities of aspartate and alanine aminotransferases post feed and water deprivation compared to the basal parameters. 
Table 1: Red blood cells and it indices in male rats deprived of feed and water for six consecutive days

\begin{tabular}{lccc}
\hline \multicolumn{1}{c}{ Parameters } & Basal & Three days postfeed and water deprivation & Six days post feed and water deprivation \\
\hline $\mathrm{RBC}\left(\mathrm{x} \mathrm{10} 10^{12} \mathrm{~L}\right)$ & $7.38 \pm 0.30^{\mathrm{a}}$ & $9.31 \pm 0.11^{\mathrm{b}}$ & $10.20 \pm 0.21^{\mathrm{b}}$ \\
$\mathrm{PCV}(\%)$ & $41.15 \pm 0.85^{\mathrm{a}}$ & $46.10 \pm 0.62^{\mathrm{b}}$ & $48.22 \pm 0.51^{\mathrm{b}}$ \\
$\mathrm{Hb}(\mathrm{g} / \mathrm{dl})$ & $14.95 \pm 0.15^{\mathrm{a}}$ & $16.01 \pm 0.11^{\mathrm{b}}$ & $18.15 \pm 0.12^{\mathrm{b}}$ \\
$\mathrm{MCV}(\mathrm{Fl})$ & $51.85 \pm 2.05^{\mathrm{a}}$ & $53.04 \pm 1.06^{\mathrm{b}}$ & $54.11 \pm 1.21^{\mathrm{b}}$ \\
$\mathrm{MCH}(\mathrm{Pg})$ & $18.25 \pm 1.25^{\mathrm{a}}$ & $16.11 \pm 1.20^{\mathrm{b}}$ & $13.15 \pm 1.21^{\mathrm{c}}$ \\
$\mathrm{MCHC}(\mathrm{g} / \mathrm{dl})$ & $38.25 \pm 1.45^{\mathrm{a}}$ & $36.12 \pm 1.33^{\mathrm{b}}$ & $34.12 \pm 1.27^{\mathrm{b}}$ \\
\hline
\end{tabular}

Values within the same rows with different superscripts are significantly different at $\mathrm{p}<0.05$. RBC: Red blood cell; PCV: Packed cell volume; Hb: Haemoglobin; MCV: Mean corpuscular volume; $\mathrm{MCH}$ : Mean corpuscular haemoglobin; MCHC: Mean corpuscular haemoglobin concentration.

Table 2: White blood and differentials in male rats deprived of feed and water for six consecutive days

\begin{tabular}{lccc}
\hline \multicolumn{1}{c}{ Parameters } & Basal & Three days post feed and water deprivation & Six days post feed and water deprivation \\
\hline TWBC (x 10\%) & $7.35 \pm 2.11^{\mathrm{a}}$ & $12.22 \pm 1.07^{\mathrm{b}}$ & $15.02 \pm 2.11^{\mathrm{b}}$ \\
Neutrophil (\%) & $6.11 \pm 2.01^{\mathrm{a}}$ & $9.37 \pm 1.03^{\mathrm{b}}$ & $11.14 \pm 1.20^{\mathrm{b}}$ \\
Eosinophils (\%) & $1.22 \pm 0.50^{\mathrm{a}}$ & $3.06 \pm 1.99^{\mathrm{b}}$ & $5.09 \pm 1.05^{\mathrm{b}}$ \\
Monocytes (\%) & $5.03 \pm 1.01^{\mathrm{a}}$ & $7.96 \pm 1.23^{\mathrm{b}}$ & $8.05 \pm 2.31^{\mathrm{b}}$ \\
Lymphocytes (\%) & $66.50 \pm 4.50^{\mathrm{a}}$ & $72.75 \pm 3.11^{\mathrm{b}}$ & $87.08 \pm 3.54^{\mathrm{b}}$ \\
\hline
\end{tabular}

Values within the same rows with different superscripts are significantly different at $\mathrm{p}<0.05$. TWBC: Total white blood cell. ( $\mathrm{p}<0.05$ ) over time compared to the basal parameters.

Table 3: biochemical parameters of male rats deprived of feed and water for six consecutive days

\begin{tabular}{lccc}
\hline \multicolumn{1}{c}{ Parameters } & Basal & $\begin{array}{c}\text { Three day days post feed and water } \\
\text { deprivation }\end{array}$ & $\begin{array}{c}\text { Six days post feed and water } \\
\text { deprivation }\end{array}$ \\
\hline Glucose (mg/dL) & $105.33 \pm 5.77^{\mathrm{a}}$ & $98.34 \pm 4.01^{\mathrm{b}}$ & $90.03 \pm 3.03^{\mathrm{b}}$ \\
Triglyceride (mg/dL) & $67.09 \pm 1.54^{\mathrm{a}}$ & $61.32 \pm 1.23^{\mathrm{b}}$ & $57.04 \pm 1.03^{\mathrm{b}}$ \\
Cholesterol (mg/dL) & $120.20 \pm 0.80^{\mathrm{a}}$ & $115.12 \pm 0.71^{\mathrm{b}}$ & $109.65 \pm 0.63^{\mathrm{b}}$ \\
Total Protein (mg/dL) & $6.80 \pm 0.10^{\mathrm{a}}$ & $9.60 \pm 0.16^{\mathrm{b}}$ & $12.12 \pm 0.32^{\mathrm{b}}$ \\
Albumin (mg/dL) & $4.14 \pm 0.04^{\mathrm{a}}$ & $4.29 \pm 0.14^{\mathrm{b}}$ & $4.98 \pm 0.13^{\mathrm{b}}$ \\
Creatinine (mg/dL) & $1.53 \pm 0.01^{\mathrm{a}}$ & $1.65 \pm 0.12^{\mathrm{b}}$ & $1.68 \pm 0.11^{\mathrm{b}}$ \\
Blood Urea Nitrogen (mg/dL) & $3.25 \pm 0.11^{\mathrm{a}}$ & $5.58 \pm 0.35^{\mathrm{b}}$ & $8.75 \pm 0.22^{\mathrm{b}}$ \\
Aspartate aminotransferase (U/L) & $120.80 \pm 0.90^{\mathrm{a}}$ & $126.34 \pm 0.75^{\mathrm{b}}$ & $134.24 \pm 0.65^{\mathrm{b}}$ \\
Alanine aminotransferase (U/L) & $34.60 \pm 0.80^{\mathrm{a}}$ & $38.76 \pm 0.65^{\mathrm{b}}$ & $42.23 \pm 0.75^{\mathrm{b}}$ \\
\hline Values within the
\end{tabular}

Values within the same rows with different superscripts are significantly different at $\mathrm{p}<0.05$.

\section{DISCUSSION}

Animals are in normal physiological state when given enough food and water, but when withdrawn, the physiological and pathological variations may take place. Food and water restriction protocols are common in animal research; however information about the physiologic and behavioral impacts of food and water restriction and the potential adverse consequences that the animal will experience as a result of the restriction are limited. Food and water deprivation will affect the animals' health, internal cellular biochemistry, behaviour, absorption rate of substances, carbohydrate and lipid metabolism (Matsuzawa and Sakazume, 1994). Studies reported in literature on the effect of feed deprivation on various haematological indices have been conflicting and inconsistent. In this study, red blood cells count, haemoglobin and hematocrit were elevated which are similar to the studies of El-Hazmi et al. (1987) and Keenan et al., (1994) who reported similar haematological increases in male rats deprived of feed and water for twenty four hours. Conversely, Dewanti et al. (2006) showed a significant decrease in hematocrit and haemoglobin concentration. The increase in the haematological parameters observed in this study is attributed to non-availability of nutrients and water needed to augment haemopoiesis, bringing about dehydration, stress and haemoconcentration. The stress could induce the spleen to push more red cells into circulation bringing about relative polycythemia which is slightly macrocytic hypochromic. The relative polycythemia and haemoconcentation bring about increase haemoglobin concentration and packed cell volume.

Total white blood cell counts, neutrophils, eosinophils, 
monocytes and lymphocyte, counts all increased over time compared to the basal parameters. Taken together, these changes in white blood cells counts are suggestive of a stress response due to feed and water deprivation. Similarly (Champy et al., 2004) reported significant increase in white cell counts in animals subjected to feed deprivation within days which was attributed to means of coping with stress induced by feed and water deprivation. The longer the animals were stressed the greater the leucocytic response (Kioukia et al., 2000).

Decreases in levels of blood glucose during fasting are due to lack of food intake and non-availability of glucose absorption from the intestines. Serum glucose concentrations in the current study were significantly lower when feed and water was deprived compared to the basal glucose levels measured when the animals were in fed state. The observation is similar to Claassen (1994) who reported decrease plasma glucose concentration in animals deprived of feed for three days. Glucose is the main supply of energy and is maintained between meals by glycogenolysis and possibly by gluconeogenesis in the liver. Glucocorticoid, insulin and glucagon also play significant role to prevent drastic fall in the glucose concentration when the animals were deprived of feed and water (Gursoy et al., 2001; Heiderstadt et al, 2000; Genn et al., 2003).

Many reports have been published on the effect of feed deprivation on blood lipids among healthy animals, with inconsistent and even conflicting findings. The discrepancy was attributed to the amount and type of food intake, physical activity and genetic makeup of the animals (Aksungar et al., 2005). We observed a decrease in the cholesterol and triglyceride concentrations in rats deprived of feed and water compared to the basal parameter, it is suggested that hormone sensitive lipase is activated leading to hydrolysis of esterified cholesterol and triglyceride. The fatty acids generated from the hydrolysis is oxidized to generate energy by the rats deprived of feed and water due to metabolic changes as glucose is not readily available as energy source ( Mahboob et al., 1999) reported decrease in plasma triglyceride concentration in human with restricted feed intake. Prolonged fasting induces an increase in plasma glucagon, plasma glucocorticoids, plasma epinephrine and a decrease in plasma insulin concentrations. This leads to hydrolysis of triglyceride in adipose tissue, which causes a rise in plasma free fatty acid concentration (Moitra et al., 1998; Kersten et al., 1999).

Protein constitutes the building block and the basic molecule for any biochemical reaction. They are intimately related with all physiological processes which maintain a simple biochemical system in living condition. The serum hyperalbuminaemia and hyperproteinaemia observed in the rats deprived of feed and water is a sharp response to dehydration and haemoconcentration. This is similar to observation by El-Hazmi et al., (1987) and Keenan et al., (1994) who reported hperproteinaemia in rats subjected to feed restriction.

Kidney is a major organ involve in body homeostasis and excretion of waste from the body. A mild azotaemia was observed in the serum which is an indication of partial clearance by the kidney. However Mgan et al., (2011) observed no significant change in the azotaemia though there was mild increase in rats subjected to short time fasting.

The liver is the organ of detoxification and involve in metabolic activities of the animals. The activities of alanine aminotransferase and aspartate aminotransferase were observed to be slightly increased in the serum of rats deprived of feed and water, which is an indication of mild hepatocellular injury due to stress on the liver. The stress resulted in the release of cytoplasmic enzymes from the liver into the serum. It is likely that lipid peroxidation could oxidize the membrane lipid leading to escape of hepatocytes content into the serum. In a study on rats subjected to feed deprivation, the hepatocellular response produces no significant change in aspartate aminotransferase (AST), alanine aminotransferase (ALT) and sorbitol dehydrogenase (SDH) after six hours of deprivation, but after 12, 24 and 36 hours of feed deprivation AST,ALT and SDH were significantly increased in deprived animals compared with non-deprived animals (Lin et al.,2005).

\section{CONCLUSIONS}

It is concluded from the data generated that, rats deprived of feed and water exhibit pronounced haematological and biochemical changes. The haematological changes ranges from dehydration to haemoconcentration, producing relative polycytheamia and viscous blood. Also there were stress induced metabolic changes in the liver and the kidney associated with the deprivation of feed and water.

\section{ACKNOWLEDGEMENT}

The author wishs to express gratitude to the University of Ilorin and the Department of Veterinary Physiology and Biochemistry, University of Ilorin for granting access to the animal house and laboratory facilities. Mr. Rahman S.A. is appreciated for sourcing healthy rats used for the study.

\section{DECLARATION OF CONFLICT OF INTEREST}

The authors declare no conflict of interest.

\section{REFERENCES}

Aksungar, F.B., Eren, A., Ure, S., Teskin, O. and Ates, G. (2005). Effects of intermittent fasting on serum lipid levels, coagulation status and plasma homocysteine levels. Annual Nutrition Metabolism 49(2): 77-82. DOI: $10.1159 / 000084739$.

Bauer, M., Hamm, A.C. and Bonaus, M. (2004). Starvation response in mouse liver shows strong correlation with life-span-prolonging processes. Physiology of Genomics 17: 230-244. DOI: 10.1152/ physiolgenomics.00203.200.

Champy, M.F., Selloum, M. and Piard, L. (2004). Mouse functional genomics requires standardization of mouse handling and housing conditions. Mammalian Genome 15:768-783. DOI: 10.1007/s00335-004-2393-1.

Claassen, V. (1994). Neglected Factors in Pharmacology and Neuroscience Research: Biopharmaceutics, Animal Characteristics, Maintenance, Testing Conditions. 
Elsevier ISBN 0-444-81907.

Dewanti, L., Watanabe, C., Sulistiawati, E. and Ohtsuka, R. (2006). Unexpected changes in blood pressure and haematological parameters among fasting and non-fasting workers during Ramadan in Indoensia. European Journal of Clinical Nutrition 60: 877-881. DOI: 10.1038/sj.ejcn.1602393.

Grant, G.H. (1987). Amino acids and Proteins; Fundamentals of Clinical Chemistry. N.W. Tietz (ed), WB Saunders Company Philadelphia USA. Pp 328329.

Gursoy, E., Cardounel, A., Hu, Y. and Muhammed, K. (2001). Biological effects of long-term caloric restriction: adaptation with simultaneous administration of caloric stress plus repeated immobilization stress in rats. Experimental Biological Medicine 226: 97-102. DOI: $10.1177 / 153537020122600206$.

Heiderstadt, K.M., McLaughlin, R., Wright, D., Walker, S. and Gomez-Sanches, C. (2000). The effect of chronic food and water restriction on open-field behaviour and serum corticosterone levels in rats. Laboratory Animals 34: 20-28. DOI: 10.1258/002367700780578028.

Henry, R.J. (1974). Colorimetric Colorimetric Determination of Creatinine in Serum: Clinical Chemistry: Principles and Techniques. $2^{\text {nd }}$ edn., Harper and Row, New York, Pp: 525-529.

Hughes, J.E., Amyx, H., Howard, J.L., Nanry, K.P. and Pollard, G.T. (1994). Health effects of water restriction to motivate lever-pressing in rats. Laboratory Animal Science 44: 135-140. PMID: 8028275.

Kanizsai, P., Garami, A., Solymar, M., Szolcsanyi, J. and Szelenyi, Z. (2009). Energetics of fasting heterothermia in TRPV1-KO and wild type mice. Physiology Behaviour 96: 149-154. DOI: 10.1016/j. physbeh.2008.09.023

Keenan, K.P., Laroque, P. and Dixit, R. (1998). Need for dietary control by caloric restriction in rodent toxicology and carcinogenicity studies. Journal of Toxicology and Environmental Health Critical Review 2: 135-148. DOI: 10.1080/10937409809524548

Kersten, S., Seydoux, J., Peters, J.M., Gonzalez, F.J., Desvergne, B. and Wrahli, W. (1999). Peroxisome proliferator activated receptor alpha mediates the adaptive response to fasting. Journal of Clinical Investigation 103: 1489-1498. DOI: 10.1172/JCI6223

Kioukia, N., Bekris, S., Antoniou, K., PapadopoulouDaifoti, Z. and Christofidis, I. (2000). Effects of chronic mild stress (CMS) on thyroid hormone function in two rat strains. Psychoneuroendocrinology 25: 247-257. DOI: 10.1016/S0306-4530(99)00051-7.

Lin, X., Yue, P., Chen, Z. and Schonfeld, G. (2005). Hepatic triglyceride contents are genetically determined in mice: results of a strain survey. American Journal of Physiology 288: G1179-G1189. DOI: 10.1152/ ajpgi.00411.2004.

Mahboob, S., Sattarivand, R., Nouri, M. and Arefhosseini, S. (1999). Effect of Ramadan fasting on serum lipids profiles in normal and hyperlipidemic subjects. Saudi Medical Journal 20: 947-950. DOI: $123456789 / 52164$

Matsuzawa, T. and Sakazume, M. (1994). Effects of fasting on haematology and clinical chemistry values in the rat and dog. Comparative Haematology International 4: 152-156. DOI: 10.1007/BF00798356.

Megan, H.N., Kelly, M.S., Hugunin, A. and Karen, L.R. (2011). Effects of Short-Term Fasting in Male SpragueDawley Rats. American Association Laboratory Animal Science 61 (2): 138-147. PMCID: PMC3079815.

McGowan, M.W., Artiss, J.D., Strandbergh, D.R. and Zak, B. (1983). A peroxidase-coupled method for the colorimetric determination of serum triglycerides. Clinical Chemistry 29: 538-542. DOI:10.1093/ clinchem/29.3.538.

Moitra, J., Mason, M.M. and Olive, M. (1998). Life without white fat: a transgenic mouse. Genes Development 12: 3168-3181. DOI: 10.1101/grad.12.20.3168.

Palou, A., Remesar, X., Arola, L.I., Herrera, E. and Alemany, M. (1981). Metabolic effects of short term food deprivation in the rat. Hormonal Metabolic Research 13: 326-333. DOI: 10.1015/s-2007-1019258.

Penicaud, L. and Le Magnen, J. (1980). Recovery of body weight following starvation or food restriction in rats. Neuroscience Biobehavioural Review 4(1): 47-52. DOI: 10.1016/0149-7634(80)90048-2.

Reitman, S. and Frankel, S. (1957). Colorimetric methods for aspartate and alanine aminotransferase. American Journal of Clinical Pathology 28: 55-60. DOI: 10.1093/ ajcp/28.1.56.

Schalm, D.W., Jain, N.C. and Carrot, E.J. (1975). Veterinary Haematology. $3^{\text {rd }}$ edn., Lea and Febiger, Philadelphia, ISBN-13: 978-0812104707, Pp:807.

Strubbe, J.H., Keijser, J.T., Dijkstra, T. and Prins, A.B. (1986). Interaction between circadian and caloric control of feeding behaviour in the rat. Physiological Behaviour 36: 489-493. DOI: 10.1016/00319384(86)90320-3.

Stricker, E.M. (1984). Biological basis of hunger and satiety: therapeutic implications. Nutritional Review 42: 333-340. DOI: 10.1111/j.1753-4887.1984.tb02249.x.

Sweileh, N., Schnitzler, A., Hunter, G.R. and Davis, B. (1992). Body composition and energy metabolism in resting and exercising muslims during Ramadan fast. Journal of Sports Medicine and Physical Fitness 32:156-163. PMID: 1434584.

Tietz, N.W. (1995). Clinical Guide to Laboratory Tests. $3^{\text {rd }}$ (ed). W.B. Saunders Company, Philadelphia. Pp. 518519.

Tucci, V., Hardy, A. and Nolan, P.M. (2006). A comparison of physiological and behavioural parameters in C57BL/6J mice undergoing food or water restriction regimes. Behavioural Brain Research 173: 22-29. DOI: 10.1016/j.bbr.2006.05.031.

Toth, L.A. and Gardiner, T.W. (2000). Food and water restriction protocols: physiological and behavioral considerations. Contemporary Tropics 39: 9-17. PMID: 11487246.

Vermeulen, J.K., De Vries, A., Schlingmann, F. and Remie, R. (1997). Food deprivation: common sense or nonsense? Animal Technology 48: 45-54.

Wingfield, J.C. and Kitaysky, A.S. (2002). Endocrine responses to unpredictable environmental events: Stress or anti-stress hormones? Integrated Comparative Biology 42: 600-609. DOI: 10.1093/ICB/42.3.600. 
Wybenga, D.R., Pileggi, V.J., Dirstine, P.I. and Di Giorgio, J. (1970). Direct manual determination of serum total cholesterol with a single stable reagent. Clinical Chemistry 16: 980-984. DOI: 10.1093/ clinchem/16.12.980. 